\title{
Yellow nail syndrome: does protein leakage play a role?
}

\author{
A. D'Alessandro, G. Muzi, A. Monaco, S. Filiberto, A. Barboni, G. Abbritti
}

\begin{abstract}
Yellow nail syndrome: does protein leakage play a role? A. D'Alessandro, G. Muzi, A. Monaco, S. Filiberto, A. Barboni, G. Abbritti. (C) ERS Journals Ltd 2001.

ABSTRACT: Yellow nail syndrome is characterized by primary lymphoedema, recurrent pleural effusion and yellow discoloration of the nails. Although mechanical lymphatic obstruction is assumed to be the underlying pathology, it cannot explain the common finding of high albumin concentration in the pleural space. This paper describes a case of yellow nail syndrome presenting with the classical triad of lymphoedema, recurrent pleural effusion and yellow discoloration of the nails, associated with persistent hypoalbuminaemia and increased enteric loss of albumin. Based on the findings in this case and those in the literature, it is speculated that increased microvascular permeability may contribute to the pathogenesis of this syndrome.

Eur Respir J 2001; 17: 149-152.
\end{abstract}

Dipartimento di Medicina Clinica E Sperimentale, Sez. di Medicina del Lavoro, Università degli studi di Perugia, Italy.

Correspondence: A. D'Alessandro, Dipartimento di Medicina Clinica, E Sperimentale, Sez. di Medicina del Lavoro, Università degli studi di Perugia, Italy. Fax: 390755783654

Keywords: Hypoalbuminaemia, lymphatic vessels, pleural effusion, yellow nail syndrome

Received: April 121999

Accepted after revision June 252000
Yellow nail syndrome is a rare syndrome characterized by primary lymphoedema, recurrent pleural effusion, and yellow discoloration of the nails [1]. Lymphatic obstruction due to anatomical abnormality is commonly assumed to be the cause. Since the first report in 1964 [1] more than 100 cases have been described in association with several disorders [2-10], but the underlying pathophysiological mechanism has not been elucidated.

\section{Case report}

A 72-yr-old white man was referred to hospital because of worsening dyspnoea, fatigue and weight loss. Eighteen years earlier, chronic bronchitis and bronchiectasis had been diagnosed. Ten years before admission, he had noted yellow discoloration of his finger nails, which were also friable and grew slowly. Six years before admission, bronchial asthma had been diagnosed. Two years before admission, a cranial computed tomography (CT) scan had shown nasal sinus thickening. One year before admission, he had suffered one episode of acute dyspnoea, with productive cough but no fever. A chest radiograph showed bilateral pleural effusions. These recurred twice after aspiration of several hundred $\mathrm{mL}$ of pleural fluid. In the six months before admission he had an episodic productive cough associated with dyspnoea and pleural effusions, intense fatigue and weight loss of $\sim 7 \mathrm{~kg}$. Two weeks before admission, after another episode of dyspnoea, a chest radiograph again showed bilateral pleural effusions. Antibiotics were started but his general condition failed to improve. The patient was then referred to hospital.

The patient, an exserviceman, had never travelled abroad, had no history of hypertension or ischaemic cardiomyopathy, had never undergone surgery and had no history of lymphangitis or tuberculosis. On admission, core body temperature was $36.8^{\circ} \mathrm{C}$, heart rate 90 and respiratory frequency $20 \cdot \mathrm{min}^{-1}$. Nonpitting oedema of the upper and lower limbs was present, together with scrotal swelling, more pronounced on the right. The fingernails were yellowish and irregularly shaped. A chest radiograph showed bilateral pleural effusions, more marked on the right side. Laboratory tests were normal except for hypoalbuminaemia and hypoproteinaemia (serum albumin on repeated assays 3.5-2.0 $\mathrm{g} \cdot \mathrm{dL}^{-1}$; total protein $\left.5.5-4.5 \mathrm{~g} \cdot \mathrm{dL}^{-1}\right)$. Pulmonary function testing showed an obstructive pattern (forced vital capacity: $1.96 \mathrm{~L}, 50 \%$ predicted forced expiratory volume in one second: $1.02 \mathrm{~L}, 36 \%$ predicted). Blood gas analysis showed mild hypoxaemia (oxygen tension in arterial blood $62.1 \mathrm{mmHg}$; carbon dioxide tension in arterial blood $36 \mathrm{mmHg}$ ). Thoracentesis yielded $\sim 1,000 \mathrm{~mL}$ fluid, with high protein and albumin concentrations (table 1) and increased lactate dehydrogenase (LDH) level, compatible with an exudative process. Serum LDH on repeated specimens ranged from $450-550 \mathrm{IU} \cdot \mathrm{L}^{-1}$ with a pleural fluid $\mathrm{LDH}$ to serum LDH ratio 0.5-0.6. The total cell count in the fluid was low and the cells were mostly lymphocytes. A chest CT scan, after repeated thoracenteses had removed $>7 \mathrm{~L}$ fluid, was indicative of minimal emphysema. Bronchoscopy was unremarkable. Bronchial aspirates were negative for bacterial or mycobacterial growth. No atypical or neoplastic cells were found in bronchial 
Table 1. - Analysis of pleural fluid

\begin{tabular}{|c|c|c|c|c|}
\hline $\begin{array}{l}\text { Biochemical profile } \\
\text { of pleural fluid }\end{array}$ & May 15 & May 22 & June 20 & July 25 \\
\hline $\begin{array}{l}\text { Glucose } \mathrm{mg} \cdot \mathrm{dL}^{-1} \\
\text { Protein } \mathrm{g} \cdot \mathrm{dL}-1 \\
\text { Albumin } \mathrm{g} \cdot \mathrm{dL}^{-1} \\
\text { Cholesterol } \mathrm{mg} \cdot \mathrm{dL}^{-1} \\
\text { Triglycerides } \mathrm{mg} \cdot \mathrm{dL}^{-1} \\
\text { Lactic dehydrogenase IU } \cdot \mathrm{L} \\
\text { Amylase } \mathrm{mg} \cdot \mathrm{dL}^{-1} \\
\text { Cell type }\end{array}$ & $\begin{array}{c}122 \\
4.3 \\
2 \\
90 \\
29 \\
283 \\
45 \\
\text { L+++ }+ \\
\text { PMN+ } \\
\text { RBC+ }\end{array}$ & $\begin{array}{c}122 \\
4.2 \\
2 \\
75 \\
25 \\
285 \\
56 \\
\text { L++ } \\
\text { PMN+ } \\
\text { RBC+ }\end{array}$ & $\begin{array}{c}117 \\
3.7 \\
1.2 \\
79 \\
33 \\
243 \\
49 \\
\mathrm{~L}++ \\
\mathrm{RBC}+\end{array}$ & $\begin{array}{l}145 \\
3.2 \\
1.4 \\
52 \\
28 \\
248 \\
44 \\
\mathrm{~L}+ \\
\mathrm{PMN}+\text { - }- \\
\mathrm{RBC}+++\end{array}$ \\
\hline
\end{tabular}

L: lymphocytes; PMN: polymorphonuclear leukocytes; RBC: red blood cells. $+:$ 10-20 cells $\cdot$ field $^{-1}(\times 40$ magnification $)$; + :

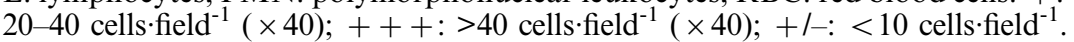

aspirates, sputum or pleural fluid. Echocardiography showed a mild pericardial effusion with no abnormality of ventricular function. Nail biopsy was negative for fungal growth. Nail fold capillaroscopy (fig. 1) showed moderately dilated and tortuous afferent and efferent capillary loops, few capillaries and moderate pericapillary oedema; photoplethysmography of both hands performed directly and after thermic stimulation, showed a marked reduction of the plethysmographic wave, compatible with severe microangiopathy. Doppler ultrasound of the lower limbs showed normal venous flow and no sign of venous insufficiency or obstruction. An abdominal ultrasound scan was normal. A scrotal ultrasound scan showed bilateral hydroceles. An abdominal radiograph after barium enema was normal; stool analysis and a xylose tolerance test showed no selective absorption disturbance. Enteric loss of albumin was studied by i.v. administration of ${ }^{51}$ Chromium-albumin followed by stool analysis. Thirty per cent of the injected albumin was recovered in the stools in the following 5 days, which represents a 10 -fold increase in normal albumin enteric loss [11]. Prealbumin, a marker of nutritional status, was assayed twice after total enteral feeding was started via a feeding tube, and was markedly lower than expected $\left(5.6 \mathrm{mg} \cdot \mathrm{dL}^{-1}\right.$; and $6.5 \mathrm{mg} \cdot \mathrm{dL}^{-1}$ normal 25-45 $\mathrm{mg} \cdot \mathrm{dL})$ [12].

Treatment was aimed at reducing the pleural effusions by thoracentesis and correction of the nutritional status. Bleomycin was administered intrapleurally to obliterate the pleural space. At discharge, pleural

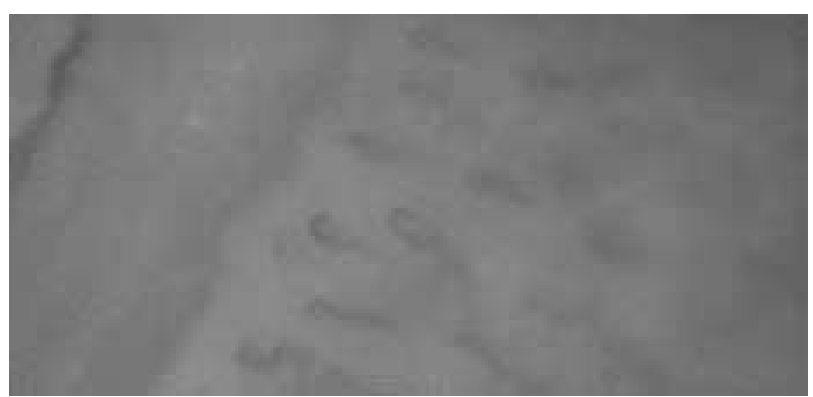

Fig. 1.- Nail fold capillaroscopy showed moderately dilated and tortuous afferent and efferent capillary loops, few capillaries and moderate pericapillary oedema. effusion was greatly reduced, dyspnoea less marked and pulmonary function test results had improved. One month later the patient was readmitted for a second bleomycin instillation. As pleural effusion was still present, the patient was transferred to a surgical unit for pleurodesis using talc. Unfortunately, after placement of pleural drainage, his general condition worsened, with the onset of severe dyspnoea and fever. He died shortly afterwards and autopsy was declined.

\section{Discussion}

It is commonly believed that yellow nail syndrome is due to an anatomical/functional abnormality of the lymphatic vessels $[1,2,10,13]$. This hypothesis would explain at least two of the three features of the syndrome, namely lymphoedema and recurrent pleural effusion. But what is the evidence to support it? SAMMAN and White [1] formulated the hypothesis in their original work on the basis of lymphangiographic evidence of lymphatic abnormality in four of the 13 cases described. Unfortunately, lymphangiography was not performed in the other nine. In a comprehensive review, NORDKILD et al. [10] summarized the results of lymphoangiographic studies in 18 patients with yellow nail syndrome performed up to 1986, and classified them according to KINMONTH et al. [14]. In only eight patients did investigators find hypoplasia of lymph trunks; however, lymphangiography is sometimes an incomplete diagnostic procedure to study the lymphatic system and some lymphatic abnormalities could be overlooked by this method. An electron microscopy study of the pleura in one case showed dilated but otherwise normal lymphatic vessels [15]. The hypothesis of a functional lymphatic vessel abnormality was further supported by RUNYON et al. [13] who measured lymphatic outflow from the pleural space in a patient with the syndrome. Based on the kinetics of radioiodinated albumin, they measured a pleural lymphatic outflow of $0.16 \mathrm{~mL} \cdot \mathrm{kg}^{-1} \cdot \mathrm{h}^{-1}$ (and a nonlymphatic formation rate of $\left.0.13 \mathrm{~mL} \cdot \mathrm{kg}^{-1} \cdot \mathrm{h}^{-1}\right)$ and concluded that this indicated a low lymphatic outflow. However, if data obtained in animal models can be extrapolated to humans, the basal lymphatic pleural outflow for a $70 \mathrm{~kg}$ human is about $0.02 \mathrm{~mL} \cdot \mathrm{kg}^{-1} \cdot \mathrm{h}^{-1}$ and it can increase up to a maximum of $0.4 \mathrm{~mL} \cdot \mathrm{kg}^{-1} \cdot \mathrm{h}^{-1}$ [16-18]. Therefore, 
the $0.16 \mathrm{~mL} \cdot \mathrm{kg}^{-1} \cdot \mathrm{h}^{-1}$ lymphatic flow found in the study of RUNYON et al. [13] was within the expected value and certainly above the basal lymphatic flow of 0.02 $\mathrm{mL} \cdot \mathrm{kg}^{-1} \cdot \mathrm{h}^{-1}$. Ironically, these results are often quoted to support the lymphatic obstruction hypothesis.

In most cases of yellow nail syndrome, the pleural fluid has a very high protein content, a moderate number of lymphocytes and no other signs of inflammation or infection (i.e. normal LDH plasma to fluid ratio). It has been suggested [2] that the standard criteria to separate transudates from exudates [19] may not be valid in this condition. The high protein and albumin concentrations in pleural effusions are again attributed $[2,10,13]$ to the lymphatic block hypothesis. However, if pleural effusions in yellow nail syndrome are due solely to a lymphatic block, hypo-oncotic fluid may be expected, since the protein concentration of the pleural fluid filtrate from systemic capillaries is rather low $\left(1 \mathrm{~g} \cdot \mathrm{dL}^{-1}\right)$. Increased protein concentration in the pleural fluid reflects increased protein permeability of systemic capillaries [17]. Indeed, pleural fluid drainage by lymphatic channels [20] leaves pleural fluid protein concentration essentially unchanged. Protein concentrations depend only on endothelial and mesothelial sieving properties i.e. on the molecular structure of the basal membrane and interstitial matrix [21]. Therefore, the high albumin content in the pleural fluid may reflect capillary leakage.

Chronic transudates can transform into exudates either spontaneously or after diuretic therapy, but pleural effusion in yellow nail syndrome is always an exudate, even from the beginning. Similarly, malignant pleural effusion due to mediastinal lymphatic obstruction, even in the absence of local pleural involvement, are usually exudates. The mechanism of exudate formation is not well understood and a combination of a higher rate of pleural fluid formation due to increased capillary permeability, and a decreased lymphatic capacity for fluid removal, has been postulated [22]. The high albumin concentration in the pleural fluid of patients with yellow nail syndrome is particularly surprising in light of the hypoalbuminaemia which is often observed in the syndrome. To explain the hypoalbuminaemia one must hypothesize a protein losing condition, provided that liver synthesis is effective. In a study of albumin turnover in one patient with yellow nail syndrome and hypoalbuminaemia using a single $i$.v . bolus of ${ }^{125}$ iodine-albumin and ${ }^{51}$ Chromium-albumin, BATTAGLia et al. [2] found that $40 \%$ of the albumin removal occurred through the gastro-intestinal tract (normally 6-9\%) and concluded that a protein-losing enteropathy was associated with a primary lymphoedema. Although enteric protein loss can be explained by lymphatic leakage alone, a condition of protein-losing enteropathy has been associated with increased capillary permeability in the capillary walls of villi [23].

Finally, in the patient, nail fold capillaroscopy and photoplethysmography of both hands were compatible with severe microangiopathy, a finding described in other cases [24]. It is also of interest to note that yellow fingernail discoloration was initially reported by SAMMAN [25] as occurring in patients affected by altered arterial circulation and particularly by Raynaud's disease.
In summary, since the theory of a pure lymphatic block is not sufficient to explain all the clinical manifestations of yellow nail syndrome, the authors suggest that microangiopathy and increased microvascular filtration at different sites (pleura, liver, limbs, intestine) due to an alteration in the interstitial matrix, could play a role in addition to lymphatic abnormality. The combination of the two mechanisms accounts for all the symptoms and particularly the hypoalbuminaemia which is associated with a high pleural fluid albumin concentration and enteric loss of protein. It also explains the cases with lymphoedema and normal lymphangiographic findings. It is impossible to generalize from a single case report and this limitation should be kept in view. Nonetheless, cases of yellow nail syndrome are rare and diagnosed on the basis of clinical signs, often without extensive physiological investigation. For that reason, much of the authors' knowledge of this condition is driven by case report data.

\footnotetext{
Acknowledgements. The authors are indebted to G. Miserocchi, P. Blanc and J. Fahy for helpful discussion and critical review of the manuscript, and to A. Funaro for providing the nail fold capillaroscopy picture.
}

\section{References}

1. Samman PD, White WF. The "yellow nail" syndrome. Br J Dermatol 1964; 76: 153-157.

2. Battaglia A, Di Ricco G, Mariani G, Giuntini C. Pleural effusion and recurrent bronchopneumonia with lymphedema, yellow nails and protein loosing enteropathy. Eur J Respir Dis 1985; 66: 65-69.

3. Dilley JJ, Kierland RR, Randall RV, Shick RM. Primary lymphedema associated with yellow nails and pleural effusion. JAMA 1968; 204: 670-673.

4. Siegelmann SS, Heckman BH, Hasson J. Lymphedema pleural effusions and yellow nails. Associated immunologic deficiency. Dis Chest 1969; 56: 114-117.

5. Parry CM, Powell RJ, Johnston IDA. Yellow nails, bronchiectasia and low circulating B cells. Respir Med 1994; 88: 475-476.

6. Rotoli M, Lesnoni Laparola I, Capizzi R, Altomonte L, Mirone L, Magarò M. Sindrome delle unghie gialle: descrizione di un caso clinico e revisione delle patologie associate. Recenti Progressi in Medicina 1990; 81: 149-151.

7. Thomas PS, Sidhu B. Yellow nail syndrome and bronchial carcinoma. Chest 1987; 92: 191.

8. Burrows NP, Russel Jones R. Yellow nail syndrome in association with carcinoma of the gall bladder. Clin Exp Derm 1991; 16: 471-473.

9. Guin JD, Ellman JH. Yellow nail syndrome. Possible association with malignancies. Arch Dermatol 1979; 115: 734-735.

10. Nordkild P, Kromann-Andersen H, StruveChristensen E. Yellow nail syndrome - the triad of yellow nails, lymphedema and pleural effusions. Acta Med Scand 1986; 219: 221-227.

11. Greenberg JN, Isselbacher JK. Disorders of Absorption. In: Isselbacher JK, Braunwald E, Wilson JD, Martin JB, Fauci AS, Kasper DL., eds. Harrison's 
Principles of Internal Medicine. XIIIth Edition. New York, McGraw Hill, pp. 1386-1403.

12. Rosenberg IH. Nutrition and Nutritional Requirements. In: Isselbacher JK, Braunwald E, Wilson JD, Martin JB, Fauci AS, Kasper DL., eds. Harrison's Principles of Internal Medicine. XIIIth Edition. New York, McGraw Hill, pp. 437-446.

13. Runyon BA, Forker EL, Sopko JA. Pleural fluid kinetics in a patient with primary lymphedema, pleural effusions and yellow nails. Am Rev Respir Dis 1979; 119: 821-825.

14. Kinmoth JB, Taylor GW, Tracy GD, Marsh JD. Primary lymphedema. Clinical and lymphangiographic studies of a series of 107 patients in which the lower limbs were affected. Br J Surg 1957; 45: 1-10.

15. Solal-Céligny $\mathrm{P}$, Cormier Y, Purnier M. The yellow nail syndrome. Light and electron microscopic aspects of the pleura. Arch Pathol Lab Med 1983; 107: 183185.

16. Miserocchi G. Physiology and pathophysiology of pleural fluid turnover. Eur Respir J 1997; 10: 219-225.

17. Miserocchi G, Venturoli D, Negrini D, Del Fabbro M. Model of pleural fluid turnover. J Appl Physiol 1993; 75: 1798-1806.

18. Miserocchi G, Negrini D. Pleural space: pressures and fluid dynamics. In: Crystal RG, West JB, Weiber ER,
Barnes PJ. The Lung: Scientific Foundations. 2nd Edition. Philadelphia, Lippincott-Raven Publishers, 1997.

19. Light RW. Pleural Effusion. Med Clin North Am 1977; 61: 1339-1352.

20. Broaddus VC, Wiener-Kronish JP, Berthiaume Y, Staub NC. Removal of pleural liquid and protein by lymphatics in awake sheep. J Appl Physiol 1988; 64: 384-390.

21. Negrini D, Passi A, De Luca G, Miserocchi G. Pulmonary interstitial pressure and proteoglycans during development of pulmonary oedema. Am J Physiol 1996; 270: H2000-H2007.

22. Light RW, Hamm H. Malignant pleural effusion: would the real cause please stand up? Eur Respir $J$ 1997; 10: 1701-1702.

23. Tsutsumi A, Sugiyama T, Matsumura R, et al. Protein losing enteropathy associated with collagen diseases. Ann Rheum Dis 1991; 50: 178-181.

24. Nougué J, Nogué-Channarond M, Parant M, Bollinelli R, Bazex J. Syndrome des ongles jaunes: Apropos de 2cas. Revue de la littérature. Ann Dermatol Venereol 1983; 110: 827-832.

25. Samman PD, Strickland B. Abnormalities of the finger nails associated with impaired peripheral blood supply. Br J Dermatol 1962; 74: 165-173. 